\title{
Hypoparathyroidism in a patient presenting with severe myopathy and skin rash. Case report and review of the literature
}

\author{
Vassiliki Syriou, Asimina Kolitsa, Lamprini Pantazi, Dimitrios Pikazis \\ Department of Pathophysiology Laiko Hospital, University of Athens, School of Medicine, Athens, Greece
}

\begin{abstract}
A 47-year old man with idiopathic hypoparathyroidism (IHP), presented as severe myopathy and skin rash is described. The serum muscle enzymes were increased. After treatment with calcium and vitamin $D$, the clinical condition improved, the skin rash gradually disappeared, and the muscle enzymes decreased and remained within the normal range thereafter.
\end{abstract}

Key words: High-creatine kinase, Hypocalcaemic myopathy, Hypoparathyroidism, Skin rash

\section{INTRODUCTION}

Hypoparathyroidism (HP) is of variable etiology and can be manifested in the neonatal period or at any age thereafter. The late onset, idiopathic form of HP is often missed because patients usually adapt to gradually established chronic hypocalcaemia. Myopathy accompanied by raised muscle enzymes has been described in nine patients with longstanding hypocalcaemia due to hypoparathyroidism ${ }^{1-8}$. The suggested pathogenetic mechanisms of myopathy and increased muscle enzymes in some patients with hypoparathyroidism do not satisfactorily interpret this association. To our knowledge, only one case of HP, myopathy and skin rash has been reported ${ }^{2}$.

Address correspondence and requests for reprints to: Vassiliki Syriou, Division of Endocrinology, Laiko Hospital, 75 Mikras Asias Str, 11527, Athens, Greece, Tel: 2107462658, Fax: 2107462664, e-mail: vasyriou@med uoa.gr

Received 24-05-05, Revised 21-06-05, Accepted 28-06-05

\section{PATIENT'S DESCRIPTION}

The patient, a 47- year old taxi-driver, married and father of two children, was admitted to the hospital with the putative diagnosis of dermatomyositis. He complained of fatigue and muscle pain in the lower extremities which had spread gradually to the pelvic and scapular girdles during the previous eight months. Involuntary muscle contractions of the legs, arms and face and facial paresthesias (numbness and tingling) were occasionally observed, while difficulty in speaking (dysphonia) and a sensation of drowning occurred infrequently. He had additionally noted a psoriatic-like rash in the lower extremities five months earlier, and also complained of an occasional sense of anxiety. His family history was negative for hypocalcaemia, diabetes mellitus, vitiligo, and autoimmune thyroid disease. There was no history of neck irradiation therapy. He mentioned moderate alcohol consumption in the past and has smoked an average of 30 cigarettes per day for the past twenty years. He has occasionally been pre- 
scribed non-steroidal anti-inflammatory drugs as well as benzodiazepines. He reported no incidence of allergies.

On physical examination the patient appeared in no distress, presenting normal mental status. A psoriatic-like rash on the legs (knees to feet) with erythematous plaques was noted (Figure 1). Proximal muscle strength was reduced. Muscle tone was normal with no fasciculations or atrophy. Deep muscle reflexes were slightly hypoactive. Trousseau's sign revealed painless, complete carpal spasm within twenty seconds. Chvostek's sign was mildly positive.

The results of routine laboratory testing were as follows: Ht: 0.379, Hb: 125 g/L, RBC: 4120000,

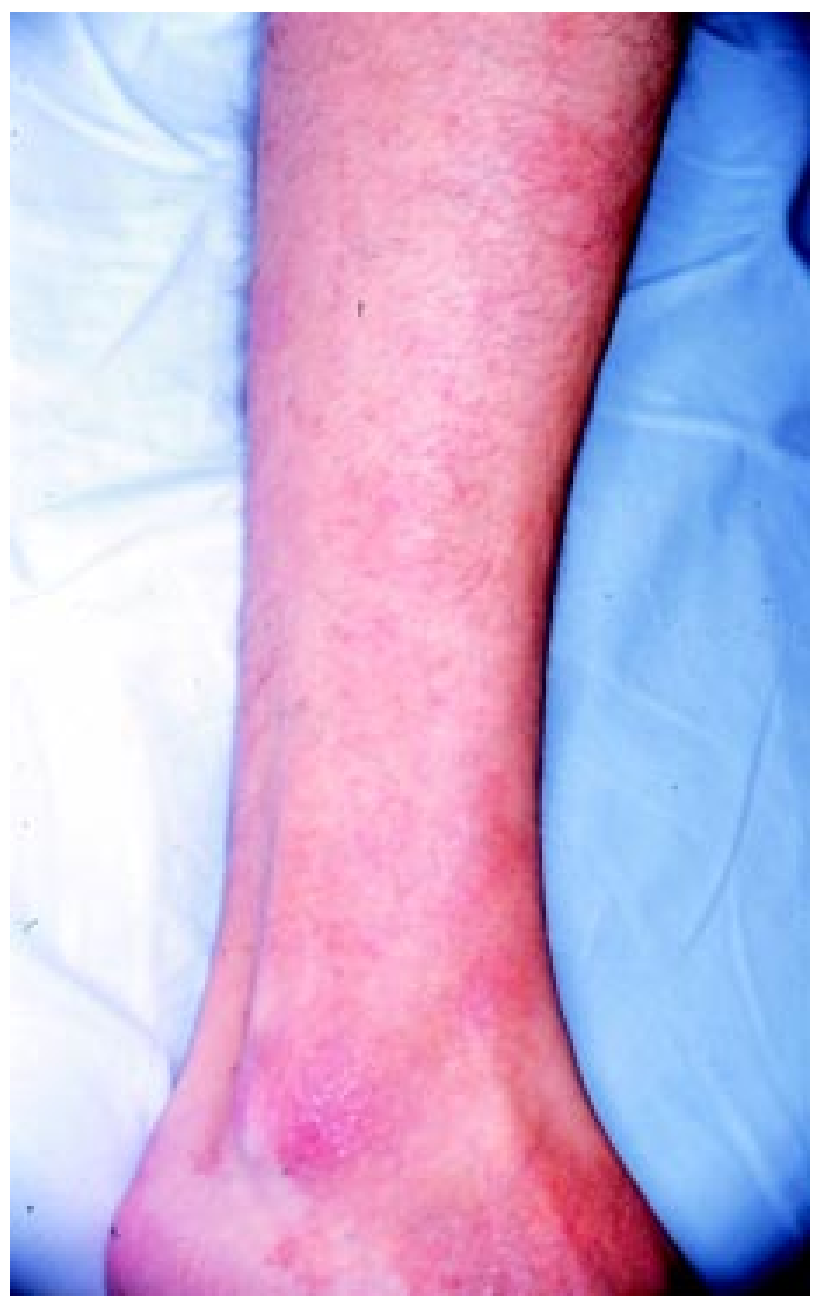

Figure 1. Skin rash in our patient with Idiopathic Hypoparathyroidism, myopathy and raised muscle enzymes. plateled: 307000, white blood cells: 12500, (neu: $71 \%$, lymp: $19.8 \%$, eos: $3.5 \%$, bas: $0.5 \%$, mono: $5.2 \%)$. The urine analysis was normal. Initial serum calcium (Ca) was $1.10 \mathrm{mmol} / \mathrm{L}$ (2.02-2.62), phosphorus $(\mathrm{P}) 2.33 \mathrm{mmol} / \mathrm{L}(0.78-1.42)$, magnesium: 0.822 $\mathrm{mmol} / \mathrm{L}(0.66-1.06)$, sodium $(\mathrm{Na}): 143 \mathrm{mmol} / \mathrm{L}(0.78$ $1.42)$, potassium $(\mathrm{K}): 3.7 \mathrm{mmol} / \mathrm{L}(3.5-5.1)$, aspartate aminotransferase: $59 \mathrm{U} / \mathrm{L}$ (5-40), creatine kinase: $3281 \mathrm{U} / \mathrm{L}(20$ - 180), alkaline phosphatase: 222 U/1 (<306), lactate dehydrogenase: 1152 U/L (200$475)$, aldolase: $17.9 \mathrm{U} / \mathrm{L}$ (1.5-12), serum total proteins: $74.4 \mathrm{~g} / \mathrm{L}$ (64.00-84.00), albumin: $52.0 \mathrm{~g} / \mathrm{L}(35.00$ $-50.00), 24 \mathrm{~h}$ urine albumin: $0.22 \mathrm{~g} / 24 \mathrm{~h}(<0.25), 24 \mathrm{~h}$ urine Ca: $1.25 \mathrm{mmol} / 24 \mathrm{~h}(1.25$ - 3.75), renal function was normal. C3 complement: $109 \mathrm{~g} / \mathrm{L}(75-140)$, C4 complement: $29.9 \mathrm{~g} / \mathrm{L}(10-34)$, anti nuclear antibody (ANA): (-), Anti - DNA: (-), anti-extractible nuclear antigens (anti-ENAs): (-), erythrocyte sedimentation rate (ESR): $50 \mathrm{~mm} / \mathrm{h}(0-20)$, C-Reactive Protein (CRP): 4 mg/ml $(<5)$, Fe: 14.68 umol/ L (10.56 - 28.28), ferritine: $451.65 \mathrm{pmol} / \mathrm{L}$ (67.41 898.80), vitamin B12: 4313 pmol/L (1644 - 6820), folic acid: $28.55 \mathrm{nmol} / \mathrm{L}(9.52-45.09)$, amylase: 124 U/L $(0-220)$, hepatitis C Virus (HCV): (-), hepatitis B surface antigen (HBsAg): (-), human immunodeficiency virus (HIV)1,2: (-).

The endocrine evaluation showed the following: Thyrotropin (TSH): $0.90 \mathrm{mU} / \mathrm{L}$ (normal 0.3-4), triiodothyronine (T3): $2.19 \mathrm{nmol} / \mathrm{L}$ (normal 0.23-3.08), thyroxine (T4): $120 \mathrm{nmol} / \mathrm{L}$ (normal 58-154), antibodies to thyroglobulin (anti-TG): (-), antibodies against thyroperoxidase (anti-TPO): (-), morning (8 a.m.) adrenocorticotropin (ACTH): $13 \mathrm{pg} / \mathrm{ml}$ (normal 10-100) and morning cortisol (F): $331.08 \mathrm{nmol} /$ L (160.022-689.75). Normal response of cortisol to IV administration of ACTH $1 \mu \mathrm{g}$. Parathyroid hormone (PTH): $1.15 \mathrm{ng} / \mathrm{L}$ (normal 8-75), 25-hydroxycholecalciferol $\left[25(\mathrm{OH}) \mathrm{D}_{3}\right]: 100.34 \mathrm{nmol} / \mathrm{L}(24.96-$ $184.70), 1.25$-hydroxycholecalciferol $\left[1.25(\mathrm{OH})_{2} \mathrm{D}_{3}\right]$ : $60 \mathrm{pmol} / \mathrm{L}(43.2-148.8)$.

The electrocardiogram (ECG) showed prolongation of Q-T interval. Chest X-ray was normal. Brain CT scanning did not reveal calcifications of the basal ganglia.

The electromyography (EMG) revealed normal sensory and motor nerve contractions, spontaneous 
muscle activity in the lower limbs, spotty degenerative motor units, with early recruitment in iliopsoas muscle and increased neuromuscular activity as expected in hypocalcaemic states.

The thyroid ultrasound was normal. The ophthalmologic examination showed unilateral posterior subcapsular cataract.

Skin biopsy revealed focal liquidous degeneration of the basal layer of the epidermis. There was fibrinogen deposition on the wall of small vessels and moderate lymphocytic infiltrations around them. Muscle biopsy was consistent with low degree non specific myopathic lesions.

The lumbar bone mineral density (BMD) (by Dual Energy X- Ray Absorptiometry: DEXA) was normal, (T-score: 0.25). Lumbar spine X-ray revealed non-significant osteophytes in the $\mathrm{L}_{4}$ vertebra.

Taking into account the clinical presentation and the laboratory findings, indicating hypoparathyroidism (HP), the patient was started on $1000 \mathrm{mg}$ Calcium Carbonate and 1mcg Alfacalcidol supplementation.

Two weeks later the patient was discharged with clinical and laboratory improvement. Ca: $1.51 \mathrm{mmol} /$ L (2.02 - 2.62), P: 1.29mmol/L (0.78 - 1.42), CPK: 1462 U/L (20 - 180), LDH: 795 U/L (200 - 475), SGOT: $32 \mathrm{U} / \mathrm{L}(5$ - 40). Treatment was modified accordingly.

One month later the patient was in complete recovery with normal laboratory findings. Ca: 2.10 $\mathrm{mmol} / \mathrm{L}$ (2.02 - 2.62), P: $1.23 \mathrm{mmol} / \mathrm{L}$ (0.81 - 1.45), CPK: 99 U/L, LDH: 229 U/L (Table 1).

Table 1. Laboratory values of some important biochemical indices and their changes during treatment with calcium and Vit. D supplementation.

\begin{tabular}{lccc}
\hline $\begin{array}{l}\text { Biochemical } \\
\text { indices }\end{array}$ & On admission & \multicolumn{2}{c}{ During treatment } \\
Two weeks & $\begin{array}{c}\text { after } \\
\text { One month } \\
\text { after }\end{array}$ \\
\hline $\mathrm{Ca}(\mathrm{mmol} / \mathrm{L})$ & 1.10 & 1.51 & 2.10 \\
$\mathrm{P}(\mathrm{mmol} / \mathrm{L})$ & 2.33 & 1.29 & 1.23 \\
$\mathrm{CK}(\mathrm{U} / \mathrm{L})$ & 3281 & 1462 & 99 \\
$\mathrm{LDH}(\mathrm{U} / \mathrm{L})$ & 1152 & 795 & 229 \\
\hline
\end{tabular}

\section{DISCUSSION}

The cause of hypoparathyroidism in our patient is not apparent. HP associated with autoimmune polyglandular syndrome is rather unlikely since other autoimmune diseases were not present either in the patient or his family. Consequently, our patient should be classified as a case of isolated idiopathic hypoparathyroidism (IHP).

Pseudohypoparathyroidism has also been reported, with findings of myopathy and increased CK values. ${ }^{1}$ Our patient did not present the clinical features of pseudohypoparathyroidism and serum PTH values were very low.

Mitochondrial myopathies may present with hypocalcaemia and raised muscle enzymes, as in Kearn-Sayers syndrome, but they usually appear during the first or second decade of life ${ }^{9,10}$ and do not readily respond to symptomatic therapy, as occurred in our patient.

The observed inverse relationship between serum $\mathrm{CK}, \mathrm{LDH}$ and calcium in our patient has also been revealed in a case of rhabdomyolysis ${ }^{4}$. The same was described in animal models ${ }^{11}$.

Virtually all previous analogous publications represent cases of IHP ${ }^{1-5,7,8,12}$. In one case with osteomalacia, myopathy and hypocalcaemia, increased CK and alkaline phosphatase values were noted ${ }^{13}$, but this is not a consistent finding in the literature.

We present a patient with hypoparathyroidism in whom the clinical picture was dominated by unusual manifestations: severe muscle weakness and skin rash leading to an initial diagnosis of dermatomyosites. The hypocalcaemia and the other clinical sings and symptoms were with appropriate therapy $^{14}$.

In the present case, $25(\mathrm{OH}) \mathrm{D}$ was normal and $1,25(\mathrm{OH})_{2} \mathrm{D}_{3}$ was low normal, as was expected ${ }^{15}$. The patient had a normal BMD of the lumbar spine, although the presence of osteophytes could be a modifying factor ${ }^{16}$. However, some authors maintain that chronic, untreated HP induces an increase in $\mathrm{BMD}^{8,17-20}$.

It is well known that the term IHP comprises a heterogeneous group of HP. The presence of Cal- 
cium-Sensing Receptor (CaSR) autoantibodies may be the explanation in many such cases. These CaSR autoantibodies may lead to a decline in the PTH release by acting as an agonist for binding to the CaSR that is normally expressed on the parathyroid cell membranes ${ }^{21}$

The presence of increased muscle enzymes in hypocalcaemic states has not as yet been adequately explained. One hypothesis could be that it is caused by tetany. The decrease in calcium concentration causes an increase in excitability at the neuromuscular junction, with a smaller degree of depolarization being needed to generate a potential. Another and more plausible hypothesis is that hypocalcaemia could induce functional alterations in the sarcolemma (increased membrane permeability) leading to the release of $\mathrm{CPK}^{2}$.

Finally, we should underline the presence of a psoriatic-like rash with erythematous plaques as a rare manifestation of hypoparathyroidism since it has been described only once in the literature as a pruritic erythematous rash $^{2}$.

In conclusion, the possibility of hypoparathyroidism should be considered in every case with hypocalcaemia and weakness since the adaptation of the organism to long-standing hypocalcaemia gives very few or non-specific symptoms and could easily be misdiagnosed.

\section{ACKNOWLEDGMENTS}

We are indebted to Prof. H. M. Moutsopoulos for his recommendations and continuous support.

\section{REFERENCES}

1. Bocchese Nora D, Fricke D, Becker J, I Gomes I, 2004 Hypocalcemic myopathy without tetany due to idiopathic hypoparathyroidism. Arq Neuropsiquiatr 62: 154-157.

2. Barber J, Butler RC, Davh MWJ, Sewry CA, 2001 Hypoparathyroidism presenting as myopathy with raised creatine kinase. Rheumatology 40: 1417-1418.

3. Snowdon JA, Macfie AC, Pearce JB, 1976 Hypocalcaemic myopathy with paranoid psychosis. J Neurol Neurosurg Psychiatry 39: 48-52.

4. Akmal M, 1993 Rhabdomyolysis in a patient with hypocalcemia due to hypoparathyroidism. Am J Nephrol 13: 61-63.
5. Ishikawa T, Inagaki H, Kanayama M, Tomoto Manzai T, 2000 Hypocalcemic hyper-CK-emia in hypoparathyroidism. Brain Dev 12: 249-252.

6. Battistella PA, Pozzan GB, Rigon F, Zancan L, Zacchello F, 1991 Autoimmune hypoparathyroidsm and hyper-CK-emia. Brain Dev 13: 61.

7. Hower J, Struck H, Tackmann W, Stolecke H, 1972 CPK activity in hypoparathyroidism. N Engl J Med 287: 1098.

8. Van Offel JF, De Gendt CM, De Clerck LS, Stevens WJ, 2000 High bone mass and hypocalcaemic myopathy in a patient with idiopathic hypoparathyroidism. Clin Rheumatol 19: 64-66.

9. Chinnery PF, Turnbull DM, 1997 Mitochondrial medicine. Q J Med 90: 657-667.

10. Harvey JN, Barnett D, 1992 Endocrine dysfunction in Kearns-Sayre syndrome. Clin Endocrinol 37: 97-103.

11. Ishikawa T, Kanayama M, Oba T, Horie T, 1998 Hypocalcemic induced increase in creatine kinase in rats. Pediatr Neurol 18: 326-330.

12. Shane E, McClane KA, Olarte MR, Bilezikian JP, 1980 Hypoparathyroidism and elevated muscle enzymes. Neurology 30: 192-195.

13. Rimaniol JM, Authier FJ, Chariot P, 1994 Muscle weakness in intensive care patients: initial manifestation of vitamin D deficiency. Intensive Care Med 20: 591-592.

14. Reginato AJ, Falasca GF, Pappu R, McKnight B, Agha A, 1999 Musculoskeletal manifestations of osteomalacia: report of 26 cases and literature review. Semin Arthritis Rheum 28: 287-304.

15. Lund Bj, Sørensen OH, Lund Bi, Bishop JE, Norman AW, 1980 Vitamin D metabolism in hypoparathyroidism. J Clin Endocrinol Metab 51: 606-609,

16. Psarrou E, Danelli AM, Malandrinou F, Singhellakis PN, 2001 Evaluating reliability of bone mass density measurements of the lumbar spine. Ostoun 12: 114120 (in Greek).

17. Abugassa S, Nordenstrom J, Eriksson S, Sjoden G, 1993 Bone mineral density in patients with chronic hypoparathyroidism. J Clin Endocrinol Metab 76: 16171621.

18. Chan FKW, Tiu SC, Choi KL, Choi CH, Kong APS, Shek CC, 2003 Increased bone mineral density in patients with chronic hypoparathyroidism. J Clin Endocrinol Metab 88: 3155-3159

19. Duan Y, De Luca V, Seeman E, 1999 Parathyroid hormone deficiency and excess: Similar effects on trabecular bone but differing effects on cortical bone. J Clin Endocrinol Metab 84: 718-722.

20. Shukla S, Gillespy T 3rd,Thomas WC Jr, 1990 The Effect of Hypoparathyroidism on the Aging Skeleton. J Am Geriatr Soc 38: 884-888.

21. Goswami R, Brown EM, Kochupillai N, et al, 2004 Prevalence of calcium sensing receptor autoantibodies in patients with sporadic idiopathic hypoparathyroidism. Eur J Endocrinol 150: 9-18. 